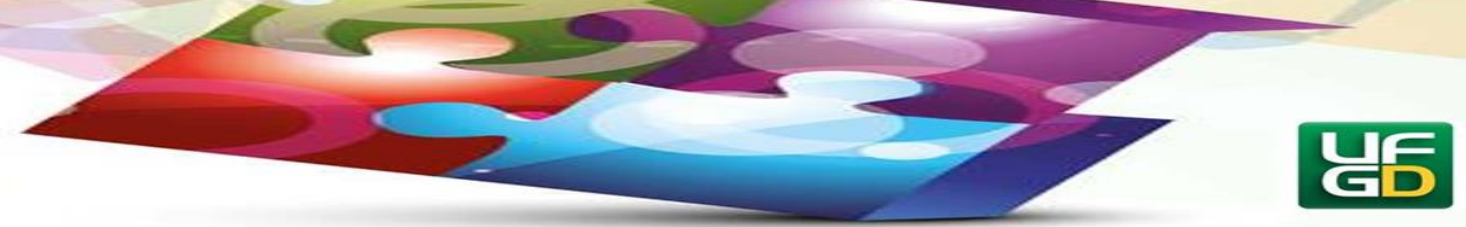

\title{
O PLANO MUNICIPAL DE EDUCAÇÃO DE CAARAPÓ - MS (2015-2025): UM ESTUDO DE SUA SISTEMATIZAÇÃO ENQUANTO DOCUMENTO
}

\author{
THE MUNICIPAL PLAN OF EDUCATION OF CAARAPÓ - MS (2015-2025): A STUDY \\ OF ITS SYSTEMATIZATION AS A DOCUMENT
}

\author{
Mayara Cristina Almeida FERNANDES ${ }^{1}$ \\ Maria Alice de Miranda ARANDA ${ }^{2}$ \\ Mara Lucinéia Marques Correa BUENO ${ }^{3}$
}

\begin{abstract}
Resumo: a presente pesquisa tem como objetivo analisar o Plano Municipal de Educação de Caarapó, MS, enquanto documento sistematizado para o período de 2015 a 2025 . A problematização foi organizada com base nos seguintes questionamentos: como se deu, na perspectiva da gestão da educação e com base no princípio da participação e da qualidade da educação e do ensino, a sistematização do PME/Caarapó (2015-2025)? Qual a concepção de gestão da educação que se pode depreender? Quem participou de sua elaboração? Qual conceito de qualidade é possível de ser detectado no documento? Os procedimentos metodológicos envolvem a pesquisa bibliográfica e documental. Na pesquisa bibliográfica, recorre-se à estudiosos do tema do planejamento educacional, da gestão da educação, da participação e da qualidade. Na pesquisa documental, ampare-se na Constituição Federal de 1988, na LDB de 1996, no PNE (2014-2024) e, em especial, no PME/Caarapó (2015-2025). A pesquisa possibilitou algumas constatações: o PME/Caarapó apresenta uma sistematização sintetizada de planejamento educacional; anuncia a gestão democrática da educação como base nas metas e estratégias; seus formuladores foram gestores das instituições de educação e ensino, em sua grande maioria, com participação relevante da sociedade civil; anuncia a prioridade para qualidade da educação e do ensino do Município. Acreditamos que a pesquisa possibilita ganhos científicos para compreender o PME de Caarapó, MS, e, em específico colabora para o aprofundamento inicial de temas inerentes a política e gestão educacional.
\end{abstract}

Palavras-Chave: Plano Municipal de Educação. Gestão Democrática da Educação. Participação.

Abstract: the present research it aims to analyze the Municipal Education Plan of Caarapó, MS, as a systematized document for the period from 2015 to 2025. The problem was organized

\footnotetext{
1 Acadêmica do Curso de Pedagogia da Faculdade de Educação da Universidade Federal da Grande Dourados (FAED/UFGD). Membro do Grupo de Estudos e Pesquisa "Estado, Política e Gestão da Educação" (GEPGE). Email: mayaracaf@hotmail.com..

${ }^{2}$ Pós-Doutora em Educação pelo PNPD/CAPES. Docente da Graduação e da Pós-Graduação (Mestrado e Doutorado) da FAED/UFGD. E-mail: mariaaranda@ufgd.edu.br.

${ }^{3}$ Doutoranda no Programa de Pós-Graduação em Educação (PPGEdu/FAED/UFGD). Professora da Universidade Federal de Mato Grosso do Sul (UFMS). E-mail:maramarquesammm@gmail.com.
} 


\section{HORIZONTES - REVISTA DE EDUCAÇÃO}

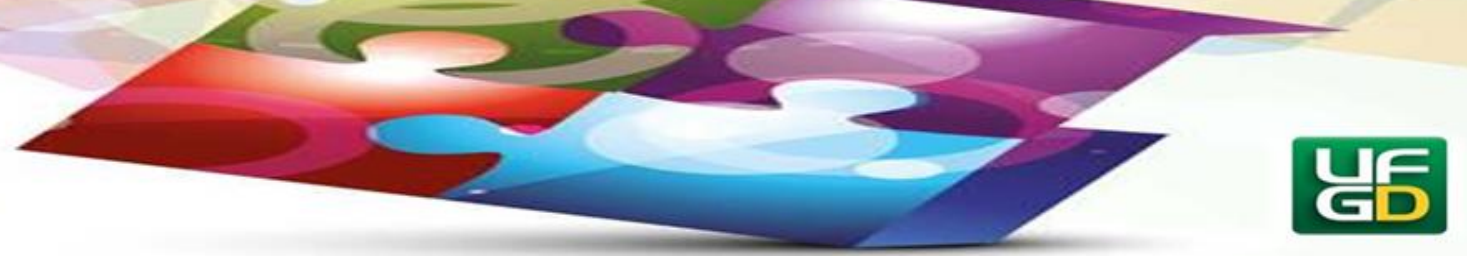

based on the following questions: as it happened, from the perspective of education management and based on the principle participation and quality of education and teaching, the systematization of PME / Caarapó (2015-2025)? What conception of education management can be understood? Who participated in its elaboration? What quality concept is possible to detect in the document? The methodological procedures involve bibliographical and documentary research. In the bibliographic research, researchers are used in the subject of educational planning, management of education, participation and quality. In the documentary research, the Federal Constitution of 1988, in the LDB of 1996, in the PNE (2014-2024) and, in particular, in the PME / Caarapó (2015-2025). The research made possible some findings: the PME / Caarapó presents a synthesized systematization of educational planning; announces the democratic management of education as the basis for goals and strategies; its formulators were managers of educational and educational institutions, most of them with relevant participation of civil society; announces the priority for the quality of education and teaching of the Municipality. We believe that the research makes possible scientific gains to understand the SME of Caarapó, MS, and in particular collaborates for the initial deepening of themes inherent to politics and educational management.

Keywords: Municipal Education Plan. Democratic Management of Education. Participation.

\section{Introdução}

O presente estudo está inserido nos Projetos de Pesquisa denominados "Monitoramento dos Planos Municipais de Educação (PMEs) do estado de Mato Grosso do Sul (MS)”, cadastrado na PROPP/UFGD e "O planejamento educacional em municípios sul-matogrossenses: do Plano de Ações Articuladas ao Plano Municipal de Educação”, cadastrado na FUNDECT- Educa MS ${ }^{4}$.

Tem como objetivo analisar o Plano Municipal de Educação do Município de Caarapó (2015-2025) ${ }^{5}$, enquanto documento legal da gestão educacional, decorrente dos preceitos elencados no Plano Nacional de Educação (2014-2024) que especifica no Artigo $8^{\circ}$ a exigência de elaboração e/ou adequação dos Planos Municipais de Educação no prazo de um ano, contado da publicação da Lei $\mathrm{n}^{\circ}$ 13.005, de 25 de julho de 2014, que aprovou o Plano Nacional de Educação (2014-2024).

De início cabe registrar que os Planos de Educação são formas de planejamento da educação brasileira, seja em nível nacional ou local, como é o caso do PME. Segundo Bartolozzi

\footnotetext{
${ }^{4}$ O primeiro Projeto de Pesquisa sob a Coordenação da Prof ${ }^{a}$. Dr ${ }^{a}$. Maria Alice de Miranda Aranda e o segundo, sob a Coordenação da Prof $^{a}$. Dr ${ }^{a}$. Elisangela Alves da Silva Scaff.

${ }^{5}$ O Plano Municipal de Educação de Caarapó- MS (2015-2025) está disponível na íntegra no seguinte endereço eletrônico: <http://www.caarapo.ms.gov.br/documentos-municipais.html>.
} 


\section{HORIZONTES - REVISTA DE EDUCAÇÃO}

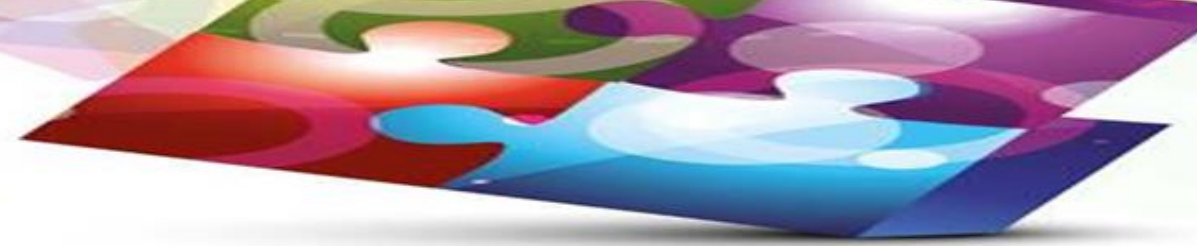

e Fonseca (2011, p. 70) “o planejamento é uma das estratégias utilizadas para imprimir racionalidade ao papel do Estado e institucionalizar 'as regras do jogo' na administração das políticas governamentais". Analisam, ainda, as autoras que o planejamento educacional pode ser permeado de concepções várias, que vão desde concepções técnicas às mais participativas.

A questão primeira que se pretende responder com este estudo é a que segue: Como está organizado o Plano Municipal de Educação (PME) de Caarapó enquanto Documento para o decênio que abarca o período de 2015 a 2025? Desta questão decorrem outras, como exemplo: quais segmentos participaram de sua elaboração? Qual tipo de gestão educacional pode ser percebido nas entrelinhas? Qual conceito de qualidade é possível de ser percebido no Documento?

Para buscar respostas, mesmo que iniciais, considerando o caráter cientifico desse estudo, vez que se trata de um Trabalho de Graduação, recorre-se metodologicamente à pesquisa bibliográfica e documental.

Com base em Severino (2007), a pesquisa bibliográfica utiliza-se de dados ou de categorias teóricas já trabalhadas por outros pesquisadores e devidamente registrados, assim os textos tornam-se, fontes dos temas as serem pesquisados. Para Marconi e Lakatos, "a pesquisa bibliográfica não é mera repetição do que já foi dito ou escrito sobre certo assunto, mas propicia o exame de um tema sob novo enfoque ou abordagem, chegando a conclusões inovadoras" (2003, p. 183).

No caso da pesquisa documental têm-se como fonte os documentos, impressos ou não, cujos conteúdos dos textos ainda não tiveram nenhum tratamento analítico, a partir da qual o pesquisador vai desenvolver sua investigação e análise (SEVERINO, 2007). E as fontes bibliográficas se definem pela natureza dos temas estudados no próprio Curso de Pedagogia, como gestão da educação, participação e qualidade do ensino.

As fontes documentais são as que seguem: Constituição Federal Brasileira de 1988, a Lei de Diretrizes e Base da Educação Nacional de 1996 (LDB), o PNE (2014-2024) e principalmente no PME de Caarapó (2015-2025).

De início, a estrutura do artigo passa pelas seguintes seções: conceitos básicos de gestão da educação, participação e qualidade educacional; na sequência tece considerações, principalmente educacionais, sobre o município de Caarapó; e, no último item, sistematiza a 


\section{HORIZONTES - REVISTA DE EDUCACÃ̃O}

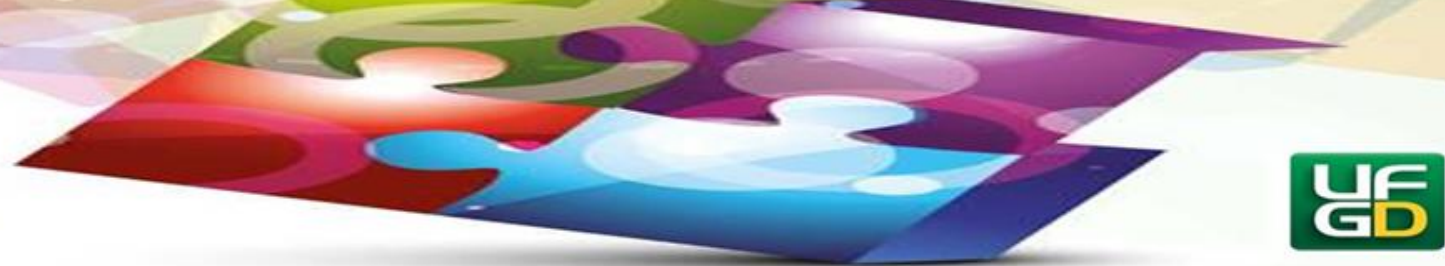

organização do PME/Caarapó (2015-2025), mostrando a sua organização enquanto

Documento.

\section{Gestão da educação, participação e qualidade da educação: conceitos básicos}

A gestão educacional, segundo Vieira (2007) abarca os processos de organização e execução sobre determinado plano, programa, leis, projeto ou ação, cujas incumbências que cada sujeito envolvido tem, se realizam a partir de tarefas destinadas por instâncias ou instituições gestoras, conforme preconizada pela legislação e em torno do chamado sistema de ensino em termos federal, estadual e municipal, a desempenhar no contexto da educação nacional.

Segundo a mesma autora (2007, p. 60) há uma diferenciação entre gestão educacional e gestão escolar, ambas definidas da seguinte forma: "A gestão educacional refere-se ao âmbito dos sistemas educacionais; a gestão escolar diz respeito aos estabelecimentos de ensino [...]”.

Paro (2010) utiliza o conceito de administração e de gestão, como sinônimos. Em seu sentido geral, a administração é a utilização racional de recursos para realização de fins determinados. No contexto escolar, isso significa que não apenas direção, serviços de secretaria [...] são de natureza administrativa, mas também a atividade pedagógica em si - aquelas que envolvem diretamente o processo ensino-aprendizado.

Para Libâneo (2004), “a gestão é a atividade pela qual são mobilizados meios e procedimentos para se atingir os objetivos da organização, envolvendo, basicamente, os aspectos gerenciais e técnico-administrativos. Nesse sentido, é sinônimo de administração".

O termo gestão para Dourado (2012) aparece como uma "nova" alternativa para o processo político-administrativo da educação. Portanto, o autor remete a gestão na concepção democrática. Analisa que:

A gestão, numa concepção democrática, efetiva-se por meio da participação dos sujeitos sociais envolvidos com a comunidade escolar, na elaboração e construção de seus projetos, como também nos processos de decisão, de escolhas coletivas e nas vivências e aprendizagens de cidadania (p. 30).

Princípios que levam a uma gestão participativa que para Luck (2010) se assenta, no entendimento de que: 


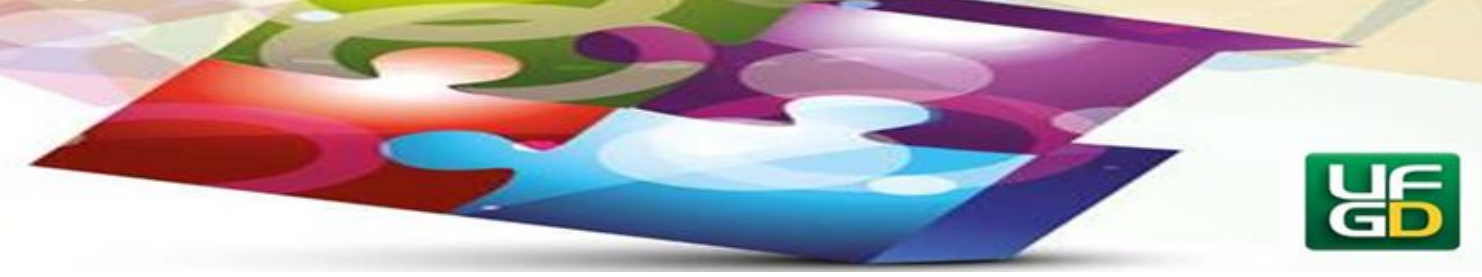

[...] o alcance dos objetivos educacionais, depende da canalização e do emprego adequado da energia dinâmica das relações interpessoais ocorrentes no contexto de sistemas de ensino e escolas, em torno de objetivos educacionais, concebidos e assumidos por seus membros, de modo a constituir um empenho coletivo em torno de sua realização (p. 23).

Segundo Libâneo (2004), a participação é o principal meio de assegurar a gestão democrática da escola, pois possibilita o envolvimento dos profissionais e usuários nas tomadas de decisões, além da melhor relação escola com a comunidade, e, favorece a aproximação de professores, alunos e pais. Portanto, “a participação é a condição básica para a gestão democrática: uma não é possível sem a outra" (GRACINDO, 2007, p. 36)

Bordenave (1983) destaca que participar significa fazer parte de algo. E, ainda, que participar significa corresponder à vontade da maioria que, muitas vezes, não tem voz no processo democrático. Enquanto que para Bordignon (2009) o termo não é apenas um bonito desejo baseado no princípio da democratização das decisões, mas uma necessidade essencial para que os sujeitos possam fazer parte de todas as questões sociais e educacionais.

Para Dourado (2012, p. 25) a participação "nas práticas e ações que a organiza deve ser eminentemente educativa, de forma a atingir os objetivos da instituição: formar sujeitos participativos, críticos e criativos".

Em termos da qualidade da educação e também do ensino, parte-se na defesa de uma qualidade socialmente referenciada, ou qualidade social, que prima pelo ser humano em sua totalidade, por isso:

[...] pode-se depreender que a qualidade na educação, por ser uma categoria dinâmica e complexa, não está imune a entendimentos dúbios, incertos, imprecisos, podendo servir a interesses vários. Por isso, é preciso buscar compreendê-la em relação à totalidade das relações sociais, com base em uma concepção 'histórico-social', portanto, crítica. Por este caminho pode-se começar a visualizar possibilidades de um projeto de sociedade, de educação e de ser humano sustentado por uma qualidade socialmente referenciada, (ARANDA E LIMA, 2014, p. 311).

Feita as considerações teóricas dos conceitos de temas que sustentam o estudo, primase na sequência, para o lócus e objeto da pesquisa efetivada.

\section{O Município de Caarapó}




\section{HORIZONTES - REVISTA DE EDUCAÇÃO}

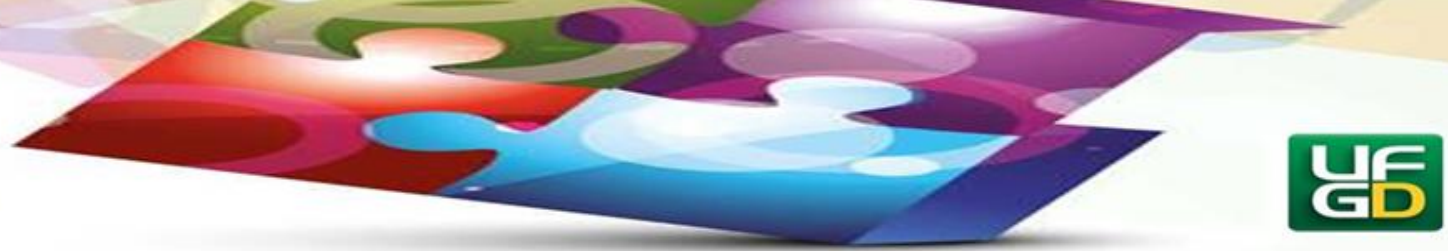

O município de Caarapó está situado ao sul do estado de Mato Grosso do Sul, a 268 km de distância de Campo Grande, sua Capital. Tem uma área de 209.000 hectares, representando 0,58\% da área total estadual. Conta com dois distritos, Nova América e Cristalina e a Aldeia Teykuê, possui uma população estimada em 2017 de 29.292 pessoas, sendo então o $15^{\circ}$ município mais populoso do estado (IBGE 2014).

O topônimo de origem tupi-guarani do nome "Caarapó" sobreveio em consequência da grande quantidade de erva-mate existente: CAA, erva-mate e RAPÓ, raiz de erva-mate, em síntese, terra da erva-mate. O povoamento do município foi iniciado em 1927, pelos empregados da Cia. Mate Laranjeira, que se dedicavam à extração da erva-mate nativa na região.

O número de Instituições no município, de acordo com o Censo do IBGE (2015) são de dez Creches Municipais do Ensino Infantil (CMEI), nove são municipais e uma é da rede privada; onze Escolas atendem o Ensino fundamental, destas quatro são municipais, seis são estaduais e uma é privada; quatro Escolas Estaduais atendem os alunos do Ensino Médio.

As matrículas na Educação Infantil em Caarapó, segundo o IBGE (2015) totalizavam 860 alunos, destes 844 estão em creches e pré-escolas municipais e 16 estão na rede privada. No Ensino fundamental estavam matriculados 4.699 alunos, na escola pública municipal 2.592 alunos e na escola pública estadual 2.119, e 88 crianças e adolescentes estavam ativos na rede privada. No ensino médio estavam matriculados 891 alunos nas escolas estaduais do município (IBGE, 2015).

Em 2015, os alunos dos anos iniciais do ensino fundamental da rede pública de Caarapó tiveram nota média de 5,5 no IDEB. Para os alunos dos anos finais, essa nota foi de 4,3. A taxa de escolarização (para pessoas de 6 a 14 anos) foi de 91,5\% em 2010. No total são 4.799 alunos matriculados no ensino fundamental (IBGE).

\section{O PME/Caarapó (2015-2024): a organização enquanto documento}

O "Plano Municipal de Educação de Caarapó - MS" (PME/Caarapó) para o decênio 2015-2025 foi instituído pela Lei Municipal N 1.255/2015, de 26 de Outubro de 2015.

Foi aprovado pela Câmara Municipal e sancionado pelo Prefeito Municipal Mário Valério. 


\section{HORIZONTES - REVISTA DE EDUCAÇÃO}

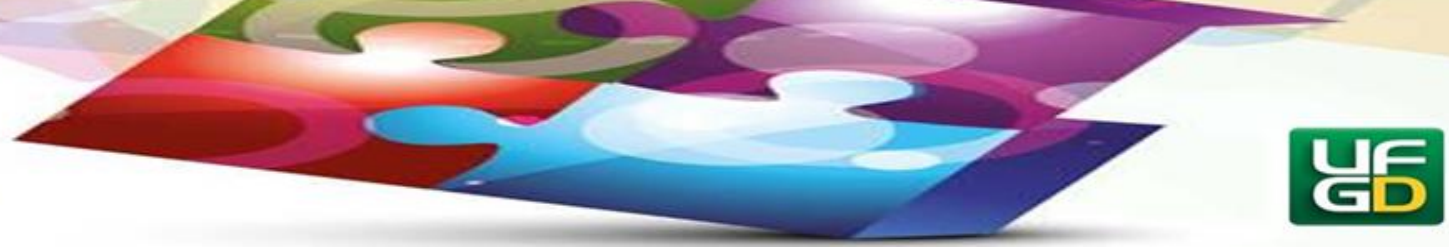

Está sistematizado em 99 páginas, com 14 Artigos. Apresenta Anexo Único contendo 20 Metas que deram origem a 286 Estratégias.

Em linhas gerais, segue no Quadro 1, uma síntese dos 14 Artigos.

Quadro 1 - Síntese dos Artigos do PME/Caarapó (2015-2025)

\begin{tabular}{|l|l|}
\hline Artigos & \multicolumn{1}{|c|}{ Síntese } \\
\hline $\mathbf{1}^{\mathbf{0}}$ & Instituição e base legal do PME/Caarapó. \\
\hline $\mathbf{2}^{\mathbf{0}}$ & Diretrizes Gerais do PME/Caarapó. \\
\hline $\mathbf{3}^{\mathbf{0}}$ & $\begin{array}{l}\text { Instâncias que participarão do monitoramento e avaliação } \\
\text { periódica do PME/Caarapó. }\end{array}$ \\
\hline $\mathbf{4}^{\mathbf{0}}$ & $\begin{array}{l}\text { Incumbência destinada aos gestores estaduais e municipais } \\
\text { para medidas governamentais necessárias ao alcance das } \\
\text { metas do PME/Caarapó. }\end{array}$ \\
\hline $\mathbf{5}^{\mathbf{0}}$ & $\begin{array}{l}\text { O Poder Público instituirá a Comissão de Monitoramento e } \\
\text { Avaliação do PME/Caarapó, }\end{array}$ \\
\hline $\mathbf{6}^{\mathbf{0}}$ & $\begin{array}{l}\text { Competências da Comissão de Monitoramento e Avaliação do } \\
\text { PME/Caarapó. }\end{array}$ \\
\hline $\mathbf{7}^{\mathbf{0}}$ & $\begin{array}{l}\text { Incumbências do Fórum Municipal de Educação de Caarapó- } \\
\text { MS - FME no acompanhamento do PME. }\end{array}$ \\
\hline $\mathbf{8}^{\mathbf{o}}$ & $\begin{array}{l}\text { Previsão de ampliação dos investimentos públicos em } \\
\text { educação, }\end{array}$ \\
\hline $\mathbf{9}^{\mathbf{0}}$ & $\begin{array}{l}\text { Definição de aprovação de leis específicas para o sistema de } \\
\text { ensino, disciplinando a gestão democrática da educação } \\
\text { pública nos respectivos âmbitos de atuação. }\end{array}$ \\
\hline $\mathbf{1 3}^{\mathbf{1 0}}$ & $\begin{array}{l}\text { Participação de instâncias permanentes de negociação, } \\
\text { cooperação e pactuação dos entes federados para o } \\
\text { cumprimento do PNE e do PEE-MS e PME. }\end{array}$ \\
\hline $\begin{array}{l}\text { Divulgação do PME por meio das diferentes mídias de } \\
\text { comunicação, portal eletrônico oficial do município, assim } \\
\text { como dos resultados do acompanhamento feito pela Comissão } \\
\text { de Monitoramento e Avaliação do PME, com total } \\
\text { transparência à sociedade. }\end{array}$ \\
\hline $\begin{array}{l}\text { Encaminhamento do próximo PME/Caarapó até o final do } \\
\text { primeiro semestre do nono ano de vigência do } \\
\text { PME atual. }\end{array}$ \\
\hline Vigência da Lei do PME/Caarapó de 2015 a 2025. \\
\hline 27 de Abril de 2007, e demais disposições em contrário. \\
\hline
\end{tabular}

Fonte: Organização própria com base no PME/Caarapó de 2015-2025.

Com vistas a trazer pontos importantes do PME/Caarapó que ofereçam resposta as questões que direcionam esta breve pesquisa, faz-se, de início, destaque para o Artigo $1^{\circ}$ : 


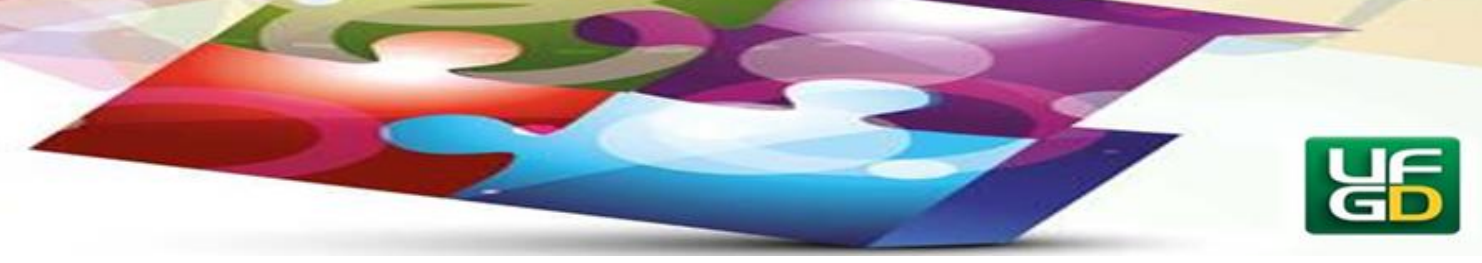

Fica instituído o Plano Municipal de Educação - PME, de Caarapó, Estado de Mato Grosso do Sul, com vigência de dez anos, a contar da publicação desta Lei, na forma do Anexo Único desta lei, com vistas ao cumprimento do disposto no art. 214 da Constituição Federal, no art. 194 da Constituição Estadual, e no art. $8^{\circ}$ da Lei Federal $n^{\circ} 13.005$, de 25 de junho de 2014, que aprovou o Plano Nacional de Educação - PNE (CAARAPÓ - PME, 2015).

Do mesmo modo e com o propósito de destacar os Incisos IV e VI, segue o Artigo $2^{\circ}$ com as 10 (dez) Diretrizes do PME/Caarapó:

I - a erradicação do analfabetismo;

II - a universalização do atendimento escolar;

III - a superação das desigualdades educacionais, com ênfase na promoção da cidadania e na erradicação de todas as formas de discriminação;

IV - a melhoria da qualidade da educação;

V - a formação para o trabalho e para a cidadania, com ênfase nos valores morais e éticos em que se fundamenta a sociedade;

VI - a promoção do princípio da gestão democrática da educação pública; VII - a promoção humanística, científica, cultural e tecnológica do País;

VIII - o estabelecimento de meta de aplicação de recursos públicos em educação como proporção do Produto Interno Bruto-PIB, que assegure atendimento às necessidades de expansão, com padrão de qualidade e equidade;

IX - a valorização dos profissionais da educação;

$\mathrm{X}$ - a promoção dos princípios do respeito aos direitos humanos, à diversidade e à sustentabilidade socioambiental (CAARAPÓ - PME, 2015, grifos nossos).

Como pode ser observado, o PME/Caarapó assegura no documento como diretrizes basilares a gestão democrática da educação para a educação pública e também anuncia a busca da qualidade da educação. Para que a gestão democrática seja real e efetiva, a participação é fundamental, é a principal forma de assegurar o êxito do Plano.

Em relação aos Artigos $3^{\circ}$ e $5^{\circ}$, para o monitoramento contínuo e avaliações periódicas, a Comissão, a ser nomeada pelo chefe do Poder Executivo, será composta pelas seguintes instâncias:

I - Secretaria Municipal de Educação e Esportes - SMEDE;

II - Secretaria de Estado de Educação- SED;

III - Ministério Público Estadual;

IV - Comissão de Educação da Câmara Municipal de Vereadores;

V - Conselho Municipal de Educação de Caarapó-MS - CME;

VI - Fórum Municipal de Educação de Caarapó-MS - FME.

VII - Conselhos/Colegiados Municipais e outros órgãos fiscalizadores; 


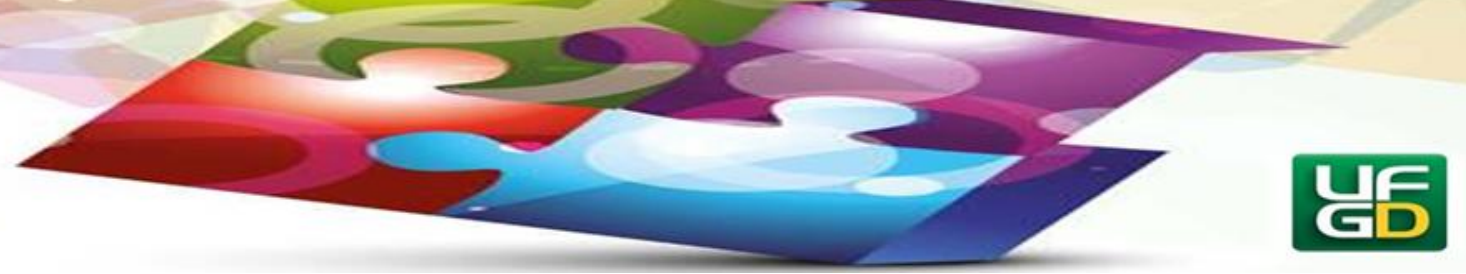

VIII - Sindicato Municipal dos Trabalhadores em Educação de CaarapóSIMTED;

IX- Associação de Pais e Mestres - APM;

X- Associação de Pais e Amigos dos Excepcionais - APAE (CAARAPÓ PME, 2015).

Em termos da participação da sociedade na elaboração do PME/Caarapó, a Secretaria Municipal de Educação e Esportes (SMEDE) de Caarapó designou uma Comissão de Elaboração que foi constituída por meio do Decreto Municipal nº 028 de 30 de março de 2015. Esta Comissão participante teve 33 (trinta e três) representantes, titulares e suplentes, de diferentes instituições educacionais e não educacionais do município, a saber:

- Secretaria Municipal de Educação e Esportes (SMEDE);

- Conselho Municipal de Educação de Caarapó;

- Secretaria de Estado de Educação (SED);

- Poder Legislativo;

- Diretores da Rede Municipal de Ensino;

- Coordenadores Pedagógicos;

- Professores da Rede Municipal de Ensino;

- Alunos da Educação Básica e do Ensino Superior;

- Departamentos de Cultura e Turismo, de Esportes, de Saúde, do Meio Ambiente e de Ação Social;

- Sindicato Municipal dos Trabalhadores em Educação (SIMTED),

- Pais de Alunos;

- Associação dos Pais e Amigos dos Excepcionais (APAE);

- Educação Escolar Indígena;

- Fórum Municipal de Educação de Caarapó;

- Transporte Escolar;

- Guarda Mirim;

- Rede Particular de Educação e de Ensino Superior.

Pelo quantitativo de representações, enquanto registro no Documento, pode se analisar que o princípio da participação foi notório, que existe a preocupação em fazer valer a vontade 


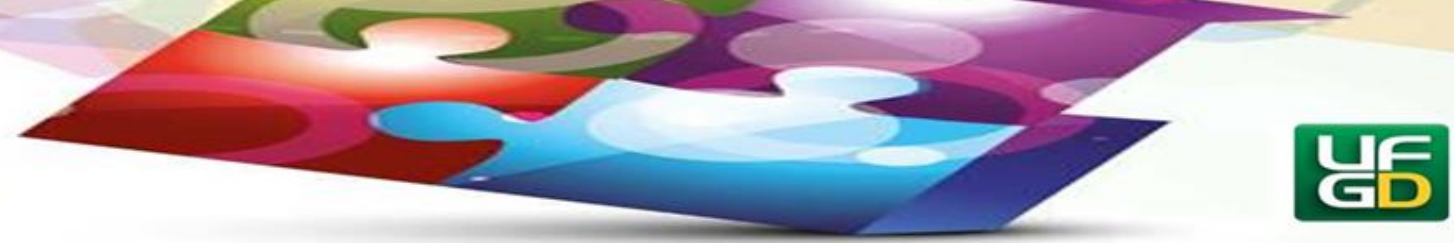

da maioria com voz no processo democrático. Isso demonstrado na teoria, vez que na prática, ou seja, no processo de implementação do PME/Caarapó não foi objeto desta pesquisa.

No Anexo Único da Lei Municipal No 1.255/2015, de 26 de outubro de 2015 estão registradas as 20 metas e 286 Estratégias. O Quadro 2 apresenta uma sistematização.

Quadro 2 - Sistematização das Metas e Quantitativos de Estratégias do PME/Caarapó (20152025)

\begin{tabular}{|c|c|c|}
\hline Metas & Descrição & $\begin{array}{c}\text { Quantitativo } \\
\text { De Estratégias }\end{array}$ \\
\hline $\begin{array}{l}\text { 1- Educação } \\
\text { Infantil }\end{array}$ & $\begin{array}{l}\text { Universalizar, até 2016, pré-escola para as } \\
\text { crianças de } 04 \text { (quatro) a } 05 \text { (cinco) anos de idade } \\
\text { e ampliar a oferta de educação infantil em creches } \\
\text { de forma a atender, no mínimo, } 50 \% \text { (cinquenta } \\
\text { por cento) das crianças de até } 03 \text { (três) anos até o } \\
\text { final da vigência deste PME. }\end{array}$ & 25 \\
\hline $\begin{array}{l}2-\text { Ensino } \\
\text { Fundamental }\end{array}$ & $\begin{array}{l}\text { Universalizar o ensino fundamental de } 09 \text { (nove) } \\
\text { anos para toda a população de } 06 \text { (seis) a } 14 \\
\text { (quatorze) anos e garantir que pelo menos } 95 \% \\
\text { (noventa e cinco por cento) dos estudantes } \\
\text { concluam essa etapa na idade recomendada, até o } \\
\text { último ano de vigência deste PME. }\end{array}$ & 19 \\
\hline $\begin{array}{l}3 \text { - Ensino } \\
\text { Médio }\end{array}$ & $\begin{array}{l}\text { Universalizar, até } 2016 \text {, o atendimento escolar } \\
\text { para toda a população de } 15 \text { a } 17 \text { anos e elevar, até } \\
\text { o final da vigência deste PME, a taxa líquida de } \\
\text { matrículas no ensino médio para } 85 \% \text {. }\end{array}$ & 19 \\
\hline $\begin{array}{l}4 \text { - Educação } \\
\text { Especial }\end{array}$ & $\begin{array}{l}\text { Universalizar, para a população de } 4 \text { a } 17 \text { anos } \\
\text { com deficiência, transtornos globais do } \\
\text { desenvolvimento e altas habilidades ou } \\
\text { superdotação, o acesso à educação básica e ao } \\
\text { atendimento educacional especializado, } \\
\text { preferencialmente na rede regular de ensino, com } \\
\text { a garantia de sistema educacional inclusivo, de } \\
\text { salas de recursos multifuncionais, classes, escolas } \\
\text { ou serviços especializados, públicos ou } \\
\text { conveniados. }\end{array}$ & 25 \\
\hline 5 - Alfabetização & $\begin{array}{l}\text { Alfabetizar, com aprendizagem adequada, todas } \\
\text { as crianças, no máximo, até o final do } 3^{\circ} \text { (terceiro) } \\
\text { ano do ensino fundamental. }\end{array}$ & 22 \\
\hline $\begin{array}{c}\text { 6- Educação } \\
\text { em Tempo Integral }\end{array}$ & $\begin{array}{l}\text { Implantar e implementar gradativamente } \\
\text { educação em tempo integral em, no mínimo,50\% } \\
\text { das escolas públicas, de forma a atender, pelo } \\
\text { menos, 25\% dos(as) estudantes da educação } \\
\text { básica. }\end{array}$ & 15 \\
\hline
\end{tabular}




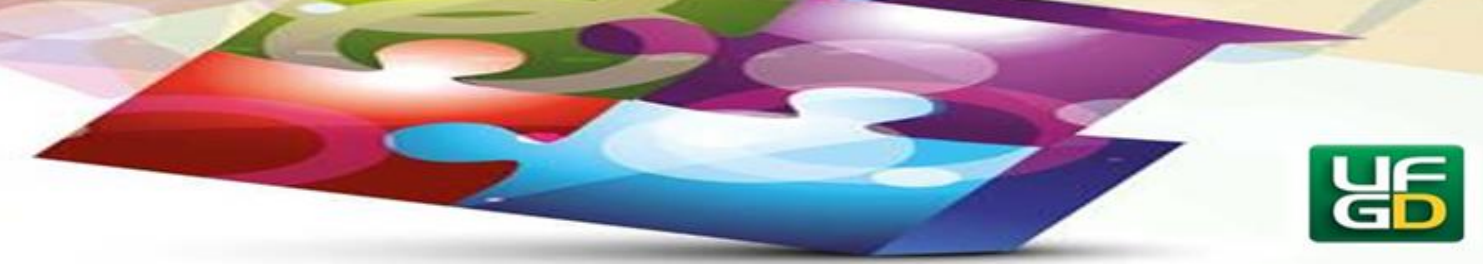

\begin{tabular}{|c|c|c|}
\hline $\begin{array}{l}7 \text { - Qualidade } \\
\text { na Educação }\end{array}$ & $\begin{array}{l}\text { Fomentar a qualidade da educação básica em } \\
\text { todas as etapas e modalidades, com melhoria do } \\
\text { fluxo escolar e da aprendizagem de modo a atingir } \\
\text { as médias nacionais para o IDEB: }\end{array}$ & 23 \\
\hline $\begin{array}{c}8 \text { - Escolaridade } \\
\text { Média }\end{array}$ & $\begin{array}{l}\text { Elevar a escolaridade média da população de } 18 \text { a } \\
29 \text { anos, de modo a alcançar, no mínimo, } 12 \text { anos } \\
\text { de estudo até o último ano de vigência deste PME, } \\
\text { para as populações do campo e dos } 25 \% \text { mais } \\
\text { pobres, e igualar a escolaridade média entre } \\
\text { negros e não negros. }\end{array}$ & 9 \\
\hline $\begin{array}{c}9 \text { - Alfabetização e } \\
\text { Analfabetismo }\end{array}$ & $\begin{array}{l}\text { Elevar a taxa de alfabetização da população com } \\
15 \text { anos ou mais para } 93,5 \% \text { até } 2015 \text { e, até o final } \\
\text { da vigência deste PME, erradicar o analfabetismo } \\
\text { absoluto e reduzir em 50\% a taxa de } \\
\text { analfabetismo funcional. }\end{array}$ & 17 \\
\hline $\begin{array}{l}10 \text { - EJA Integrada } \\
\text { a Educação } \\
\text { Profissional }\end{array}$ & $\begin{array}{l}\text { Oferecer, no mínimo, } 25 \% \text { das matrículas de } \\
\text { educação de jovens e adultos na forma integrada à } \\
\text { educação profissional, nos ensinos fundamental e } \\
\text { médio. }\end{array}$ & 11 \\
\hline $\begin{array}{l}11 \text { - Educação } \\
\text { Profissional } \\
\text { Técnica de Nível } \\
\text { Médio }\end{array}$ & $\begin{array}{l}\text { Triplicar as matrículas da educação profissional } \\
\text { técnica de nível médio, assegurando a qualidade } \\
\text { da oferta e pelo menos } 50 \% \text { da expansão no } \\
\text { segmento público. }\end{array}$ & 14 \\
\hline $\begin{array}{l}12-\text { Ensino } \\
\text { Superior }\end{array}$ & $\begin{array}{l}\text { Elevar a taxa bruta de matrícula na educação } \\
\text { superior para } 50 \% \text { e a taxa líquida para } 33 \% \text { da } \\
\text { população de } 18 \text { a } 24 \text { anos, assegurada a qualidade } \\
\text { da oferta e expansão para, pelo menos, } 40 \% \text { das } \\
\text { novas matrículas, no segmento público. }\end{array}$ & 12 \\
\hline $\begin{array}{l}13-\text { Ensino } \\
\text { Superior }\end{array}$ & $\begin{array}{l}\text { Garantir que as IES que atuam ou vierem atuar no } \\
\text { município possuam } 75 \% \text { (setenta e cinco por } \\
\text { cento) de mestres e doutores no corpo docente, em } \\
\text { efetivo exercício no conjunto do sistema de } \\
\text { educação superior, sendo, do total, no mínimo, } \\
35 \% \text { (trinta e cinco por cento) } \\
\text { doutores. }\end{array}$ & 6 \\
\hline \multirow[t]{2}{*}{$\begin{array}{c}14-\text { Ensino } \\
\text { Superior }\end{array}$} & $\begin{array}{l}\text { Elevar gradualmente o número de matrículas na } \\
\text { pós-graduação stricto sensu, contribuindo dessa } \\
\text { forma para atingir a titulação anual de } 60.000 \\
\text { (sessenta mil) mestres e } 25.000 \text { (vinte e cinco mil) } \\
\text { doutores, no território nacional. }\end{array}$ & 9 \\
\hline & $\begin{array}{l}\text { Garantir, em regime de colaboração entre a União, } \\
\text { os Estados, o Distrito Federal es Municípios, no } \\
\text { prazo de um ano de vigência deste PME, política } \\
\text { nacional de formação dos profissionais da } \\
\text { educação de que tratam os incisos I, II e III do }\end{array}$ & \\
\hline
\end{tabular}




\section{HORIZONTES - REVISTA DE EDUCAÇÃO}

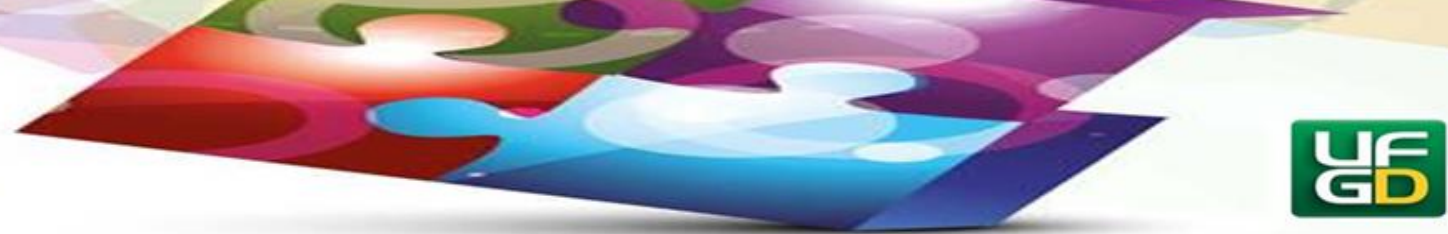

\begin{tabular}{|c|c|c|}
\hline $\begin{array}{l}15 \text { - Valorização } \\
\text { Profissional }\end{array}$ & $\begin{array}{l}\text { caput do art. } 61 \text { da Lei Federal } n^{\circ} 9.394 \text {, de } 20 \text { de } \\
\text { dezembro de } 1996 \text {, assegurado que todos(as) } \\
\text { os(as) professores(as) da educação básica } \\
\text { possuam formação específica de nível superior, } \\
\text { obtida em curso de licenciatura na área de } \\
\text { conhecimento em que atuam. }\end{array}$ & 9 \\
\hline $\begin{array}{l}16 \text { - Valorização } \\
\text { Profissional }\end{array}$ & $\begin{array}{l}\text { Formar, em nível de pós-graduação, } 50 \% \text { dos(as) } \\
\text { professores(as) da educação básica, até o último } \\
\text { ano de vigência deste PME, e garantir a todos(as) } \\
\text { os(as) profissionais da educação básica formação } \\
\text { continuada em sua área de atuação, considerando } \\
\text { as necessidades, demandas e contextualizações } \\
\text { dos sistemas de ensino. }\end{array}$ & 10 \\
\hline $\begin{array}{l}17 \text { - Valorização } \\
\text { Profissional }\end{array}$ & $\begin{array}{l}\text { Valorizar os(as) profissionais do magistério das } \\
\text { redes públicas de educação básica de forma a } \\
\text { equiparar seu rendimento médio aos dos(as) } \\
\text { demais profissionais com escolaridade } \\
\text { equivalente, até o final do sexto ano de vigência } \\
\text { deste PME. }\end{array}$ & 3 \\
\hline $\begin{array}{c}18 \text { - Valorização } \\
\text { Profissional }\end{array}$ & $\begin{array}{l}\text { Assegurar, no prazo de dois anos, a existência de } \\
\text { Planos de Carreira para os(as) profissionais da } \\
\text { educação básica e superior pública e, para o Plano } \\
\text { de Carreira dos(as) profissionais da educação } \\
\text { básica pública, tomar como referência o piso } \\
\text { salarial nacional profissional, definido em lei } \\
\text { federal, nos termos do inciso VIII do art. } 206 \text { da } \\
\text { Constituição Federal. }\end{array}$ & 9 \\
\hline $\begin{array}{l}19 \text { - Gestão } \\
\text { Democrática }\end{array}$ & $\begin{array}{l}\text { Assegurar condições, no prazo de dois anos, para } \\
\text { a efetivação da gestão democrática da educaçãa, } \\
\text { associada a critérios técnicos de mérito e } \\
\text { desempenho e à consulta pública à comunidade } \\
\text { escolar, no âmbito das escolas públicas prevendo } \\
\text { recursos e apoio técnico da União. }\end{array}$ & 13 \\
\hline $\begin{array}{l}20- \\
\text { Financiamento } \\
\text { da Educação }\end{array}$ & $\begin{array}{l}\text { Ampliar o investimento público em educação } \\
\text { pública de forma a atingir, no mínimo, o patamar } \\
\text { de } 7 \% \text { do Produto Interno Bruto (PIB) do País no } \\
5^{\circ} \text { ano de vigência deste PME e, no mínimo, o } \\
\text { equivalente a } 10 \% \text { do PIB ao final do decênio. }\end{array}$ & 16 \\
\hline
\end{tabular}

Fonte: Organização própria com base no PME/Caarapó de 2015-2025.

Como se pode notar no Quadro 2, o PME/Caarapó primou por priorizar todos os temas que dão materialidade a educação, inclusive, a título de informação, registra-se que o tema do 


\section{HORIZONTES - REVISTA DE EDUCAÇÃO}

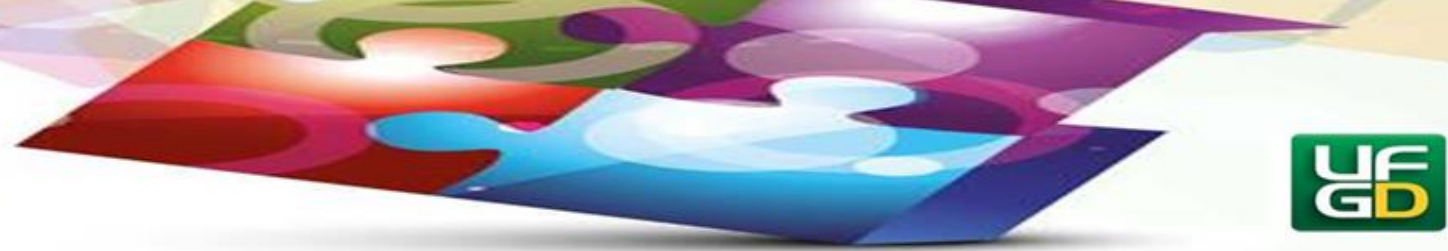

ensino superior está presente nas metas 12, 13 e 14 e da valorização profissional nas metas 15, 16,17 e 18 .

Em linhas gerais, o PME/Caarapó faz destaque nos diagnósticos sistematizados ao longo suas metas e estratégias, para muitos pontos do setor educacional do Município. Está ressaltada no Plano que um dos princípios norteadores da Educação Municipal de Caarapó é a universalização do acesso à escola, garantia de permanência, de sucesso e da qualidade do ensino, gestão democrática, mas que ainda enfrentam grandes dificuldades para a oferta de um atendimento com qualidade.

Como exemplo, em relação à meta para a Educação Infantil, está o desafio do atendimento às crianças de zero a seis anos, a ausência da definição de políticas de financiamento para esta etapa da Educação Básica. Mas, mesmo diante desta realidade o município tem feito investimentos de recursos próprios principalmente nas Creches. Intenta, entre suas estratégias, promover em parceria com as Instituições de Ensino Superior - IES, com os Programas de Pós-Graduação, para a formação inicial e continuada dos (as) professores (as) da educação infantil, garantindo o atendimento das crianças por docentes com formação superior na área de atuação e formação continuada (CAARAPÓ - PME, 2015).

Quanto à meta para o Ensino Fundamental, o PME/Caarapó reafirma o PNE (20142024) quanto a universalizar o ensino de 09 (nove) anos para toda a população de 06 (seis) a 14 (quatorze) anos e garantir que pelo menos $95 \%$ (noventa e cinco por cento) dos estudantes concluam essa etapa na idade recomendada, até o último ano de vigência deste PME (CAARAPÓ - PME, 2015).

Ainda sobre o Ensino Fundamental, o PME/Caarapó registra que muitos desafios precisam ser enfrentados no Ensino fundamental, a exemplo de: abandono dos estudos, distorção idade-série; problemas econômicos e sociais; problemas de ordem pedagógica e escolar como despreparo da escola e docentes para a inclusão de estudantes com necessidades educacionais específicas; aulas descontextualizadas da vida dos estudantes; estudantes desestimulados e sem perspectivas de futuro e, por fim, falta de compromisso dos pais com a aprendizagem e educação dos filhos.

Para o Ensino Médio, a meta apresenta a proposição de universalizar, até 2016, o atendimento escolar para toda a população de 15 a 17 anos e elevar, até o final da vigência deste 


\section{HORIZONTES - REVISTA DE EDUCACÃ̃O}

e-ISSN: 2318-1540

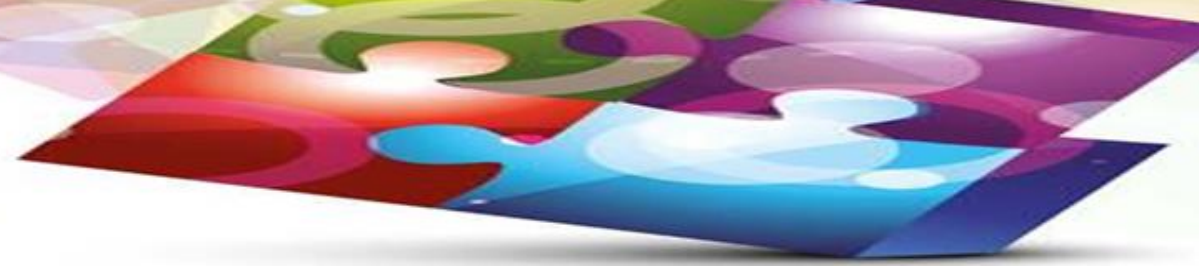

PME, a taxa líquida de matrículas no ensino médio para $85 \%$, considerando também a questão problemática da permanência e continuidade dos estudos (CAARAPÓ - PME, 2015).

$\mathrm{O}$ atendimento com qualidade para a Educação Especial é também uma grande meta, para isso, entre muitas estratégias está a busca pela qualidade de vida destes estudantes com deficiência, Para isso, assegurar parcerias com diversos órgãos públicos, privados e Organizações Não-Governamentais, com instituições comunitárias, confessionais ou filantrópicas sem fins lucrativos, conveniadas com o poder público, é o aminho, bem como ampliar a oferta de formação continuada aos profissionais da educação e a produção de material didático acessível, assim como os serviços de acessibilidade necessários ao pleno acesso, participação e aprendizagem dos (as) estudantes com necessidades educacionais específicas, matriculados (as) na rede pública de ensino (CAARAPÓ - PME, 2015).

Outra grande meta do PME/Caarapó é a Alfabetização considerando os grandes desafios que decorrem quando se pretende uma escola democrática, em que todos os estudantes tenham acesso a uma educação de qualidade. Para tanto, está a previsão de continuidade do Pacto Pela Alfabetização na Idade Certa - PNAIC ${ }^{6}$, instituído pela Portaria n ${ }^{\circ} 867$, de 4 de julho de 2012 (CAARAPÓ - PME, 2015).

Também a Educação em Tempo Integral está prevista no PME/Caarapó, nas estratégias está a previsão de que a formação do estudante seja feita, além da escola, com a participação da família e da comunidade, com forte incentivo a participação dos pais ou responsáveis no acompanhamento das atividades escolares dos filhos (CAARAPÓ - PME, 2015).

Na meta que trata da Qualidade na Educação, o Índice de Desenvolvimento da Educação Básica (IDEB) ocupa destaque e a tabela abaixo está registrada no PME/Caarapó e sistematiza a caminhada pretendida que iniciou em 2015 e vai até 2021.

\footnotetext{
${ }^{6}$ Conferir Aranda (2017).
} 


\section{MORIZONTES - REVISTA DE EDUCAÇÃO}

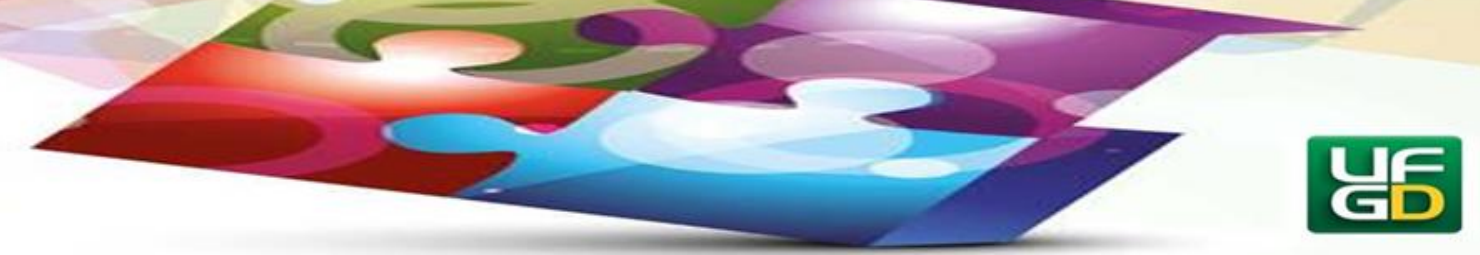

Tabela 1 - IDEB em Caarapó- MS (2015-2021)

\begin{tabular}{c|c|c|c|c}
\hline IDEB & $\mathbf{2 0 1 5}$ & $\mathbf{2 0 1 7}$ & $\mathbf{2 0 1 9}$ & $\mathbf{2 0 2 1}$ \\
\hline $\begin{array}{c}\text { Anos iniciais do Ensino } \\
\text { Fundamental }\end{array}$ & 5,2 & 5,5 & 5,7 & $\mathbf{6 , 0}$ \\
\hline $\begin{array}{c}\text { Anos finais do Ensino } \\
\text { Fundamental }\end{array}$ & 4,7 & 5,0 & 5,2 & $\mathbf{5 , 5}$ \\
\hline Ensino Médio & 4,3 & 4,7 & 5,0 & $\mathbf{5 , 2}$ \\
\hline
\end{tabular}

Fonte: PME/Caarapó - MS (2015-2025).

Além do IDEB, mas priorizando-o, muitas outras estratégias estão listadas com o objetivo de assegurar a qualidade da educação e do ensino: participação dos professores da Rede Pública de Ensino nos Programas de Formação Continuada em Serviço, oferecidos pela Secretaria Municipal de Educação e Esportes (SMEDE) e Secretaria de Estado de Educação (SED); continuidade do Programa Mais Educação; Avaliação Diagnóstica Inicial e Final com objetivo de avaliar o desempenho dos alunos; elaborar planejamento estratégico; executar o Planos de Ações Articuladas, entre outras (CAARAPÓ - PME, 2015).

Em relação à meta que trata da Escolaridade Média da população de 18 a 29 anos, está a divulgação e incentivo, de forma permanente, a participação em exames gratuitos de certificação da conclusão dos ensinos fundamental e médio, bem como, formular, em parceria com outros órgãos e instituições, currículos adequados às especificidades dos (as) estudantes da EJA, incluindo temas que valorizem os ciclos/ fases da vida, a promoção da inserção no mundo do trabalho e a participação social (CAARAPÓ - PME, 2015).

No que diz respeito a meta que relaciona Alfabetização e Analfabetismo está a efetivação do controle social e da fiscalização sobre a qualidade dos cursos da Educação de Jovens e Adultos (EJA) por meio de avaliação institucional; em seguida está a meta que destaca a EJA integrada a Educação Profisssional e depois a Educação Profissional Técnica de Nível Médio (CAARAPÓ - PME, 2015).

No que tange ao Ensino Superior, registrado nas metas 12, 13 e 14, que respectivamente destacam a elevação de matrículas nas graduações, a necessidade de quadro qualificado de docentes mestres e doutores nas IES instaladas em Caarapó - MS, e, a elevação de matrículas nos Programas de Pós-Graduação stricto sensu. Nas estratégias estão listadas: o mapeamento da demanda de formação de pessoal de nível superior, destacadamente no que se refere à formação nas áreas de ciências e matemática; o estimulo a participação de estudantes no Exame 


\section{MORIZONTES - REVISTA DE EDUCAÇÃO}

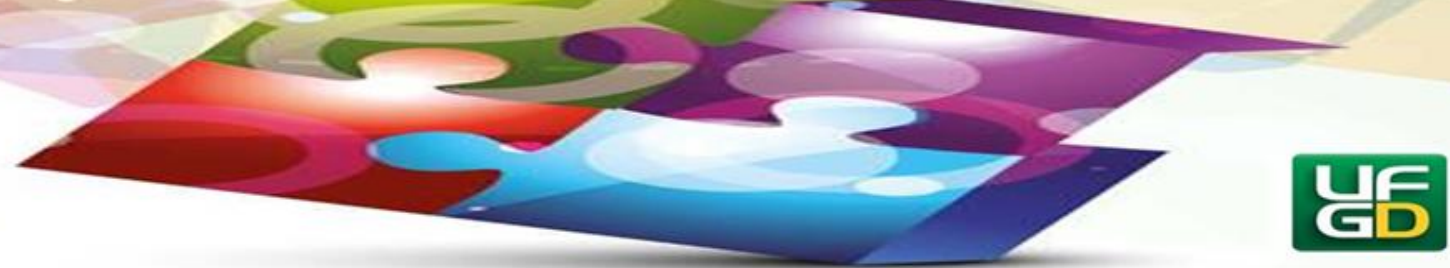

Nacional de Desempenho de Estudantes - ENADE; participação em pesquisa institucionalizada, articulada a programas de pós-graduação stricto sensu, visando elevar o padrão de qualidade das IES; e o apoio às políticas de estímulo à participação de mulheres nos cursos de pós-graduação stricto sensu, em particular naqueles ligados às áreas de Engenharia, Matemática, Física, Química, Informática, e outros no campo das ciências (CAARAPÓ - PME, 2015).

As metas 15, 16, 17 e 18 dizem respeito à valorização profissional, com destaque para a garantia de política nacional de formação dos profissionais da educação de modo que todos possuam formação específica de nível superior, obtida em curso de licenciatura na área de conhecimento em que atuam, bem como garantir que 50\% dos professores tenham também a formação em nível de pós-graduação até o último ano de vigência do PME, e, ainda, assegurar, no prazo de dois anos, a existência de Planos de Carreira para os (as) profissionais da educação básica e superior pública e para os profissionais da educação básica pública, tomar como referência o piso salarial nacional profissional, definido em lei federal (CAARAPÓ - PME, 2015).

Na meta denominada gestão democrática, o prazo de dois anos a contar da homologação da Lei de aprovação do PME/Caarapó, está posta a sua efetivação, cujo pilar de decisões e escolhas passa pela consulta pública da comunidade escolar, a exemplo da Eleição de Diretor. Dentro do rol de estratégias, está o fortalecimento dos conselhos/colegiados escolares e demais Conselhos Municipais, como instrumentos de participação e fiscalização na gestão escolar e educacional; do Fórum Municipal de Educação (FME), em regime de colaboração com o Fórum Estadual de Educação de Mato Grosso do Sul (FEEMS); as Conferências Municipais e Estaduais de Educação; da formulação participativa do Projeto Político Pedagógico; da avaliação de docentes e gestores escolares; dos processos de autonomia pedagógica, administrativa e de gestão financeira nos estabelecimentos públicos de ensino (CAARAPÓ PME, 2015).

\section{Registra o PME/Caarapó:}

Para que a gestão democrática seja real e efetiva, a participação da comunidade é fundamental, pois discutindo, refletindo e interferindo como sujeito, fará com que a gestão democrática se realize concretamente na prática do cotidiano escolar. A participação é a principal forma de assegurar este 


\section{HORIZONTES - REVISTA DE EDUCAÇÃO}

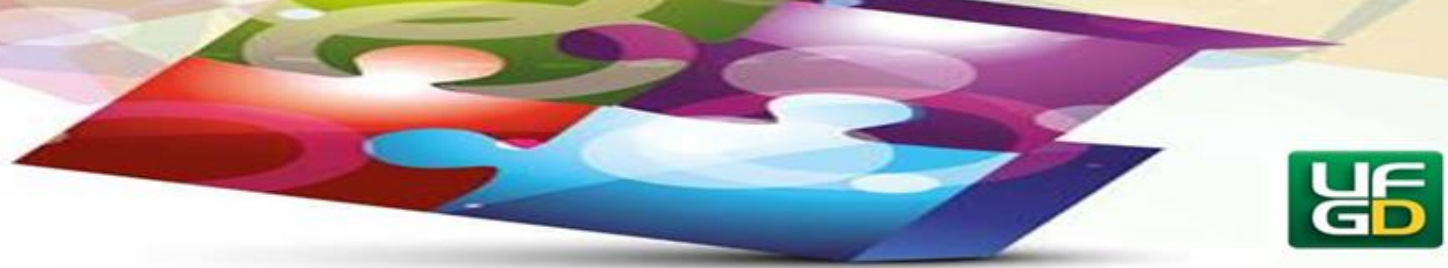

processo, pois é ela que permite a integração dos profissionais, dos estudantes e da comunidade na organização escolar (CAARAPÓ, PME, 2015, p. 89).

A última meta especifica o financiamento da educação, que como explicitada no Quadro 2 pretende atingir, no mínimo, o patamar de 7\% do Produto Interno Bruto (PIB) do País no $5^{\circ}$ ano de vigência deste PME e, no mínimo, o equivalente a 10\% do PIB ao final do decênio.

E dentre as estratégias está a garantia: de fontes de financiamento permanentes e sustentáveis para todos os níveis, etapas e modalidades da educação básica; de aplicação, na íntegra, os percentuais mínimos de recursos vinculados para a educação pública em todos os níveis, etapas e modalidades; ampliação do investimento público em educação pública em relação ao PIB; assegurar as matrículas em educação especial, ofertadas por organizações filantrópicas, comunitárias e confessionais, parceiras do poder público, e sua contabilização para fins de financiamento com recursos públicos da educação básica; ampliar e reestruturar as unidades escolares e capacitar os(as) profissionais para atender a demanda da educação inclusiva; assegurar o transporte escolar, as atividades artístico-culturais e o esporte (CAARAPÓ - PME, 2015).

E em relação a valorização dos profissionais da educação, garantir o cumprimento do piso salarial profissional nacional previsto em lei para carga horária de 20 horas aos(às) profissionais do magistério público da educação básica (CAARAPÓ - PME, 2015).

\section{Considerações finais}

O presente estudo teve como objetivo analisar o Plano Municipal de Educação do Município de Caarapó - MS (2015-2025), enquanto documento legal da gestão educacional, conforme imperativo legal dado pelo Plano Nacional de Educação (2014-2024) que normatizou a elaboração e/ou adequação dos Planos Municipais e Estaduais de Educação no prazo de um ano, contado da publicação da Lei n ${ }^{\circ} 13.005$, de 25 de julho de 2014.

Teve, portanto, como questão primordial indagar como está organizado o Plano Municipal de Educação de Caarapó para o decênio 2015 a 2025?

Nessa direção, como resposta à questão, o PME de Caarapó foi analisado em relação a sua estruturação e por meio dos registros que demarcam suas diretrizes, metas e estratégias, trazer de modo resumido toda sua organização. 


\section{HORIZONTES - REVISTA DE EDUCAÇÃO}

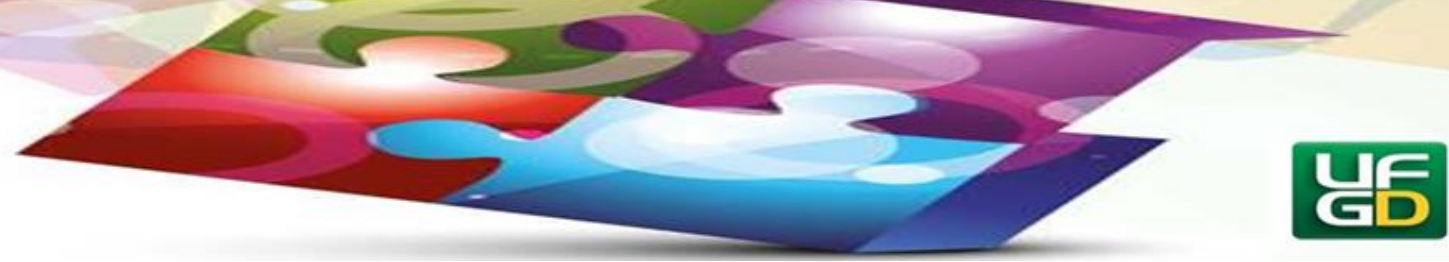

Assim, a proposição não ultrapassou o nível de apresentação do Documento, ou seja, não buscou verificar cientificamente como está ocorrendo a sua implementação, o seu desenvolvimento no movimento social, político, financeiro e, principalmente, educacional, considerando que dois se passaram de sua implantação.

Conforme colocado no início, o PME é uma modalidade do Planejamento Educacional e este pode ser permeado de concepções várias, que vão desde concepções técnicas às mais participativas. Foi nesse sentido que outras questões decorrentes da questão central foram feitas em relação ao PME/Caarapó, enquanto um Documento. Retomamdo-as: quais segmentos participaram de sua elaboração? Qual tipo de gestão educacional pode ser percebido nas entrelinhas? Qual conceito de qualidade é possível de ser percebido no Documento?

Em relação a participação da sociedade civil, e nesta a educacional, como também a sociedade política, 33 (trinta e três) Instituições e grupos participaram. Em relação à busca e garantia da gestão educacional, está em relevo a gestão democrática da educação, bem como a busca pela garantia da qualidade da educação e do ensino. Afirmações escritas e também perceptíveis nas entrelinhas.

Em suma, do mesmo modo, prima-se por deixar evidente nesse estudo a sua necessária continuidade, com vistas a buscar saber, por meio de pesquisas posteriores, como a participação, a gestão democrática da educação e também a qualidade pretendida, estão sendo concretizadas no movimento educacional, vez que são diretrizes revestidas de aprendizado no dia a dia e luta constante daqueles que acreditam na educação brasileira.

Dito isso, embora seja necessário finalizar a escrita desse texto, reafirma-se que não se encerram aqui as reflexões, dúvidas e expectativas que ele despertou, pois a investigação de um processo tão complexo como o de elaboração de um Plano para a Educação suscita o interesse em acompanhar seu processo de implementação, o qual se encontra diretamente relacionado às mudanças no quadro político nacional do Brasil contemporâneo.

\section{Referências}

ARANDA, M. A. de M.; LIMA, F. R. O Plano Nacional de Educação e a Busca pela Qualidade Socialmente Referenciada. Educação e Políticas em Debate, v. 3, 2014. p. 291313. Disponível em: http://www.seer.ufu.br/index.php/revistaeducaopoliticas. Acesso em dez.2017. 


\section{MORIZONTES - REVISTA DE EDUCAÇÃO}

e-ISSN: 2318-1540

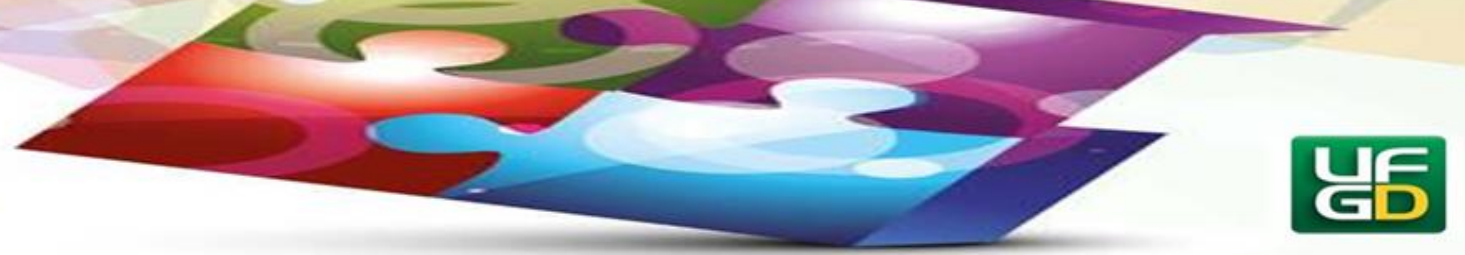

ARANDA, M. A. de M. O Pacto brasileiro de alfabetização nos municípios de Dourados-MS e Uberlândia-MG: política educacional e gestão escolar. Laplage em Revista (Sorocaba), ISSN 2446-6220, vol.3, n.3, set.-dez. 2017, p.164-177. Disponível em:

http://www.laplageemrevista.ufscar.br/. Acesso em dez. 2017.

BORDENAVE. J. E. D. O que é participação? São Paulo: Brasiliense, 1983.

BORDIGNON, G. Gestão da educação no município: Sistema, Conselho e Plano. São Paulo: Paulo Freire, 2009.

BRASIL. Constituição da República Federativa do Brasil de 1988. Brasília, DF, Presidência da República, 1988.

BRASIL. Lei $n^{\circ}$ 9.394, de 20 de dezembro de 1996. LDB. Estabelece as diretrizes e bases da educação. DF, Brasil, 1996.

BRASIL. Lei $n^{\circ} 13.005$, de 25 de julho de 2014. Aprova o Plano Nacional de Educação PNE e da outras providências. DF, Brasil, 2014.

CAARAPÓ. Plano Municipal de Educação de Caarapó - MS (2015 a 2025). Instituído pela Lei Municipal no 1.255 de 2015. Caarapó, Brasil, 2015. Disponível em http://www.caarapo.ms.gov.br/documentos-municipais.html. Acesso em set. 2017.

DOURADO, L. F. Gestão da educação escolar. 4 ed. atualizada e revisada - Cuiabá: Universidade Federal de Mato Grosso / Rede e-Tec Brasil 2012, 102p.

DOURADO, L. F.; OLIVEIRA, J. F. A qualidade da educação: perspectivas e desafios. Caderno Cedes, Campinas vol. 29, n. 78, p. 201-215, maio/ago. 2009. Disponível em http://www.cedes.unicamp.br. Acesso em out.2017.

FONSECA, M.; FERREIRA, E. B. O planejamento das políticas educativas no Brasil e seus desafios atuais. Perspectiva, Florianópolis, v. 29, n. 1, 69-96, jan./jun. 2011. Disponível em: http://www.perspectiva.ufsc.br. Acesso em dez. 2017.

GRACINDO, R. V. Gestão democrática nos sistemas e na escola. Brasília: Universidade de Brasília, 2007.

IBGE. Instituto Brasileiro de Geografia e Estatística. 2015. Disponível em 2https://cidades.ibge.gov.br/brasil/ms/caarapo. Acesso em nov. 2017.

LIBÂNEO, J. C. Organização e gestão da escola: teoria e prática. 5 ed. Revista e ampliada. Goiânia: Editora Alternativa, 2004.

LUCK, H. Dimensões da Gestão Escolar e suas Competências. 6 ed. Curitiba: Positivo, 2009. A gestão participativa na escola. 6 ed. Petrópolis. Vozes, 2010. 


\section{HORIZONTES - REVISTA DE EDUCACÃO}

LAKATOS, E. M; MARCONI, M. A. Fundamentos de metodologia científica. 5. ed. São Paulo. Atlas, 2003.

PARO, V. H. A educação, a política e a administração: reflexões sobre a prática do diretor de escola. Educação e Pesquisa, São Paulo, v. 36, n.3, p. 763-778, set./dez. 2010

SEVERINO, A. J. Metodologia do trabalho científico. 23. ed. rev. e atual. São Paulo: Cortez, 2007.

VIEIRA, S. L. Política(s) e Gestão da Educação Básica: revisitando conceitos simples. Revista Brasileira Política e Administração da Educação, v.23, n.1, jan./abr. 2007. Disponível em: http://seer.ufrgs.br/rbpae/article/viewFile/19013/11044. Acesso em: 03 jun. 2017.

Enviado: 03/08/2018

Aceito: $24 / 08 / 2018$ 